\title{
Influence of headspace pressure on methane production in Biochemical Methane Potential (BMP) tests.
}

\author{
David Valero ${ }^{\mathrm{a}}$, Jesús A. Montes ${ }^{\mathrm{a}}$, José Luis Rico ${ }^{\mathrm{b}}$, Carlos Rico ${ }^{\mathrm{a},}$
}

${ }^{a}$ Department of Water and Environmental Science and Technologies, University of Cantabria, Avda. Los Castros, s/n, 39005, Santander, Spain

${ }^{b}$ Department of Chemical and Process Engineering Resources, University of Cantabria, Avda. Los Castros, s/n, 39005, Santander, Spain.

* Corresponding author. Tel.: +34 942201848; fax: +34 942201703.

E-mail address: ricoc@unican.es (Carlos Rico)

\begin{abstract}
The biochemical methane potential test is the most commonly applied method to determine methane production from organic wastes. One of the parameters measured is the volume of biogas produced which can be determined manometrically by keeping the volume constant and measuring increases in pressure. In the present study, the effect of pressure accumulation in the headspace of the reactors has been studied. Triplicate batch trials employing cocoa shell, waste coffee grounds and dairy manure as substrates have been performed under two headspace pressure conditions. The results obtained in the study showed that headspace overpressures higher than 600 mbar affected methane production for waste coffee grounds. On the contrary, headspace overpressures within a range of 600-1000 mbar did not affect methane production for cocoa shell and dairy manure. With the analyses performed in the present work it has not been possible to determine the reasons for the lower methane yield value obtained for the waste coffee grounds under high headspace pressures.
\end{abstract}

Keywords: Headspace pressure; BMP test; Cocoa shell; Waste coffee grounds; Dairy manure. 
Abbreviations

$\begin{array}{ll}\text { AD } & \text { Anaerobic digestion } \\ \text { BA } & \text { Bicarbonate alkalinity } \\ \text { BMP } & \text { Biochemical methane potential } \\ \text { COD } & \text { Chemical oxygen demand } \\ \text { COD }_{\text {biodegradable }} & \text { Biodegradable COD } \\ \text { COD }_{\text {VFA }} & \text { COD due to volatile fatty acids } \\ \text { CS } & \text { Cocoa shell } \\ \text { DM } & \text { Dairy Manure } \\ \mathbf{P}_{\text {amb }} & \text { Ambient pressure } \\ \mathbf{P}_{\text {headspace }} & \text { Headspace overpressure } \\ \mathbf{P}_{\text {STP }} & \text { Standard pressure } \\ \text { T }_{\text {STP }} & \text { Standard temperature } \\ \text { TKN } & \text { Total kjeldahl nitrogen } \\ \text { TS } & \text { Total solids } \\ \text { V }_{\text {headspace }} & \text { Headspace volume } \\ \text { VFA } & \text { Volatile fatty acids } \\ \text { VS } & \text { Volatile solids } \\ \text { WCG } & \text { Waste coffee grounds }\end{array}$




\section{Introduction}

Anaerobic digestion (AD) is an attractive sustainable environmental technological process that stabilizes organic wastes and produces renewable energy in the form of biogas and nutrient rich and hygienized digestate (Nkemka et al., 2015). Organic matter can be characterized by either chemical or biological methods. Different methods have been recommended to determine the anaerobic biodegradability and methane potentials for organic substrates (Lesteur et al., 2010). The Biochemical Methane Potential (BMP) test is the most commonly applied method to determine biogas and methane production from organic substrates (Angelidaki et al., 2009; Godin et al., 2015; Koch et al., 2015; Strömberg et al., 2014). The method is performed at laboratory scale and provides information on both the quantity of methane which can be produced from a specific substrate, and also the speed at which the production occurs.

Despite the wide use of BMP tests, no commonly accepted experimental procedure yet exists that is based on a standardized protocol for the execution of the test (Koch et al., 2015; Murovec et al., 2015). Koch et al., (2015) reported that there are two main protocols applied for performing the BMP test. Of these, one is the method published by the Task Group for the Anaerobic Biodegradation, Activity and Inhibition of the Anaerobic Digestion Specialist Group of the International Water Association (IWA) in 2009 (Angelidaki et al., 2009). The other one is the technical guideline VDI 4630 (VDI 4630, 2006), performed by the Association of German Engineers (Verein Deutscher Ingenieure, VDI). The ISO Guideline 11734 (ISO 11734, 1995) also describes the method to evaluate the ultimate anaerobic biodegradability of organic compounds in digested sludge.

At laboratory scale there are basically two methods to measure biogas production in BMP tests: volumetrically by providing constant pressure and measuring the volume of 
biogas by displacement volume devices, or manometrically by keeping the volume constant and measuring increases in pressure (Rozzi and Remigi, 2004; Parajuli, 2011). The first time that portable pressure transducer devices were used in methanogenic activity tests date from 1988 (Concannon et al., 1988). The use of pressure transducers simplifies the set-up of the experiment. The volume of gas produced can be calculated from the measured overpressure. A gas release device must be available to reduce pressure to avoid high pressures during the test. Headspace pressure is an experimental condition that can affect the test (Angelidaki et al., 2009). Recently, Koch et al. (2015) studied the influence of the headspace flushing gas on methane production in the BMP test. Although some studies have been performed on the effect of high pressure on the performance of the continuous AD process (Chen et al., 2014; Lindeboom et al., 2011, 2012), to the best of our knowledge there are no previous works in which the effect of pressure accumulation in the headspace reactors in BMP tests had been studied. According to these studies, $\mathrm{CO}_{2}$ and $\mathrm{pH}$ in the medium, as well as bacteria growth, are affected by high pressures.

The importance of headspace pressure accumulation lies in the fact that the BMP test generally takes 30-60 days (Labatut et al., 2011). When venting is done manually, it might not be possible to measure the pressure and release the produced gas daily during the experiment. In addition, it might not be necessary to take very frequent pressure measures and subsequent venting which would also reduce the time and resources (chromatography for methane determination) used in the test.

This study is a first approach to evaluate the impact of headspace pressure accumulation on the performance of BMP tests by manometric biogas volume determination. The impact of this experimental parameter on the calculated BMP has been investigated for three complex organic wastes: dairy manure, waste coffee 
grounds and cocoa shell.

\section{Materials and Methods}

\subsection{Substrates and inoculum}

Dairy manure (DM) was collected from the cow house of a 500-free stall dairy cow farm in the Santander area (Northern coast of Spain). Waste coffee grounds (WCG) were collected from the cafeteria of the Civil Engineering Faculty in the University of Cantabria. Cocoa shell (CS) was obtained from a dairy milk processor that manufactures milk chocolate products. A coffee mill was used to reduce the CS particle size (size $<1 \mathrm{~mm}$ ). Anaerobically digested liquid fraction of dairy manure was used as inoculum (I). Previous to the BMP tests, the inoculum was degassed for five days at $38^{\circ} \mathrm{C}$.

\subsection{Experimental set-up}

Because the objective of the work was to study the effect of headspace pressure accumulation on methane production, the BMP tests did not follow any of the standardized protocols above mentioned.

Two experimental conditions were compared. For the first condition (P0), the reactors were initially vented daily as was necessary to maintain low pressures in the headspace. After that, the reactors were vented nearly every day. In this way, high continuous overpressures were avoided. For the second condition (P1), the reactors were vented when the headspace overpressure reached a threshold of $800 \pm 200$ mbar. Three control reactors (one for each substrate) were used to follow the pressure evolution of P1 reactors. To compare the results from experiments $\mathrm{P} 0$ and $\mathrm{P} 1$, a statistical analysis was 
performed to determine if the differences between both the experiments were significant or not for the different substrates tested. The statistical analysis was performed using SPSS software. The significance of the differences between values obtained under different pressure conditions was assessed using the Student's t-test. Values of $\mathrm{P}<0.05$ were considered significant.

For each substrate and condition, the tests were carried out in 250-mL triplicate serum bottles capped with rubber septum sleeve stoppers. Aiming to keep the pressures within the selected range for P1 conditions, and based on earlier assays, each reactor was filled with $175 \mathrm{~g}$ of a mixture consisting of dechlorinated tap water, inoculum (I) and substrate (S) (see Table 2). Nitrogen was flushed to remove the air in the headspace of the bottles. Thereafter, all the reactors were placed in an incubator at $38^{\circ} \mathrm{C}$ for a period of 35 days. All the reactors were manually agitated once a day. Three blanks with $100 \mathrm{~g}$ of water and $75 \mathrm{~g}$ of inoculum were also tested to measure methane potential of the inoculum. Results are expressed as means \pm SD subtracting methane production from the inoculum.

\subsection{Numerical calculations}

The cumulated volumes of methane were calculated by the cumulative summation of methane volumes determined each time headspace pressure was measured and the biogas was released by venting. Equation 1 shows the conversion of headspace pressure to volume of biogas at standard pressure and temperature based on the ideal gas law.

$$
\text { (1) } V_{\text {biogas_STP }}=V_{\text {headspace }} \cdot \frac{P_{\text {headspace }}}{P_{S T P}} \cdot \frac{T_{S T P}}{T}
$$

In Equation 1, $\mathrm{V}_{\text {biogas-STP }}$ is the volume of biogas, adjusted to standard pressure and temperature $\left(0^{\circ} \mathrm{C}, 1 \mathrm{~atm}\right)$, and produced between two venting operations. $\mathrm{V}_{\text {headspace }}$ is 
the reactor headspace volume, $\mathrm{P}_{\text {headspace }}$ is the manometric pressure measured in the headspace, $\mathrm{P}_{\text {STP }}$ is the standard pressure (1013.25 mbar), $\mathrm{T}_{\text {STP }}$ is the standard temperature in $\mathrm{K}(273.15 \mathrm{~K})$ and $\mathrm{T}$ is the operation temperature $(311.15 \mathrm{~K})$. In equation 2 the conversion of the methane biogas content from wet to dry conditions is shown.

$$
\text { (2) } \% \mathrm{CH}_{4 \_ \text {dry }}=\% \mathrm{CH}_{4_{-} w e t} \cdot\left(1-\frac{P_{\text {vap }}}{P_{\text {amb }}+P_{\text {headspace }}}\right)
$$

In Equation 2, \% $\mathrm{CH}_{4-\mathrm{dry}}$ is the biogas methane content in dry gas conditions whereas $\% \mathrm{CH}_{4 \text {-wet }}$ is the analyzed biogas methane content (wet conditions). $\mathrm{P}_{\text {vap }}$ is the vapor pressure of water at operation temperature (65.50 mbar). $\mathrm{P}_{\mathrm{amb}}$ is the ambient pressure which was set at a constant value of 1013.25 mbar (the experiment was carried out at sea level). The methane production between two venting operations can be calculated according to Equation 3, in which $\triangle \mathrm{V}_{\mathrm{CH} 4}$ is the volume of methane produced in each venting time interval. $\% \mathrm{CH}_{4} \_$dry_previous is the methane content of biogas (dry conditions) at the beginning of a venting cycle $\left(\mathrm{P}_{\text {headspace }}=0\right)$ whereas $\% \mathrm{CH}_{4}$ _dry_current is the methane content of biogas (dry conditions) at the end the venting cycle $\left(\mathrm{P}_{\text {headspace }}>0\right)$.

$$
\begin{aligned}
& \text { (3) } \Delta V_{C H 4}=\left(V_{\text {headspace }} \cdot \frac{T_{S T P}}{T}+V_{\text {biogas_STP }}\right) \cdot \frac{\% C H_{4 \_d r y \_c u r r e n t}}{100} \\
& -\left(V_{\text {headspace }} \cdot \frac{T_{S T P}}{T}\right) \cdot \frac{\% C H_{4_{\_} \text {dry_previous }}}{100}
\end{aligned}
$$

\subsection{Analytical Techniques}

The manometric pressure was measured in the headspace of the reactors through the septum with a syringe connected to a digital pressure transducer with silicon measuring cell (ifm, Germany - type PN78, up to 2000 mbar). The biogas samples were also taken through the septum by a needle connected to a syringe. The biogas composition was 
measured on a 2m Poropak T column in a HP 6890 gas chromatograph (GC) System with helium as the carrier gas and a TCD detector. The methane volumes are expressed at $0^{\circ} \mathrm{C}$ and $1 \mathrm{~atm}$. Volatile fatty acids (VFA) were determined using a HP6890 GC fitted with a 2 m 1/8-in glass column, liquid phase 10\% AT 1000, packed with solid-support Chromosorb W-AW 80/100 mesh. Nitrogen was used as the carrier gas at a flow rate of $14 \mathrm{~mL} / \mathrm{min}$, and a FID detector was installed. Total Solids (TS), Volatile Solids (VS) and Total Kjeldahl Nitrogen (TKN) were analyzed using Standard Methods (APHA, 1998). The $\mathrm{pH}$ was measured with a glass electrode $\mathrm{pH}$ meter (WTW, SENTIX 21). The bicarbonate alkalinity (BA) was determined by titration according to the method described by Anderson and Yang (1992).

\section{Results}

\subsection{Composition of substrates}

The characteristics of the substrates and the inoculum are shown in Table 1. From the high VS content of WCG (40\%) and CS (82.3\%), high methane yields per mass of these substrates are expected. The $\mathrm{C} / \mathrm{N}$ ratio was similar for the three substrates, which ranged from 20.2 (CS) to 22.9 (WCG). Because TKN content (in terms of TS) was also similar for the three substrates, the protein content can also be considered as similar (protein content can be estimated as total $\mathrm{N}$ x 6.25). Regarding fiber content, the literature reports the following values (g/100 g dry matter): 15.1 (CS), 12.4 (WCG) and

26.8 (DM) for cellulose; 15.3 (CS), 39.1 (WCG) and 7.9 (DM) for hemicellulose; 13.7 (CS), 23.9 (WCG) and 11.4 (DM) for lignin (Ballesteros et al., 2014; Labatut et al., 2011; Serra and Benería, 1998).

\subsection{Headspace pressure}


Fig. 1 shows the manometric pressure profile for the three substrates: CS, WCG and DM under P0 and P1 conditions. Under P0 conditions all reactors were vented twenty one times in a 35-day-period of experimentation. Two different behaviours can be observed. On the one hand, for the CS and the DM there was a clear peak on the first overpressure measurement (621 and 583 mbar for CS and DM respectively). With the exception of that peak, the overpressure always maintained values lower than 200 mbar for the CS and the DM. On the other hand, the pressure profile for WCG0 did not show a clear peak, remaining at values between 200-400 mbar during the first ten days of the test. After day 10, pressure values were consistently lower than 200 mbar. During the last days of the experiment, daily pressure values diminished progressively dropping to negligible values at the end of the test.

For P1 condition, a similar pressure profile was observed for the CS and the DM. Three vents were done on days 5, 14 and 35. For CS1 the mean pressure values ranged between 1023 mbar (day 5) and 580 mbar (day 35). For DM, the mean pressure values ranged between 1175 mbar (day 5) and 543 mbar (day 35). As the experiment progressed, the time interval between venting operations was increased and the pressures reached were lower. As stated previously, the WCG1 pressure profile was different from CS1 and DM1. On the one hand, the WCG1 reactor required four venting operations. On the other hand, WCG1 only spent four days between the first and the second venting. Moreover, the range of accumulated pressures was narrower than those for CS1 and DM1 and the highest pressure value was observed in the second venting operation (day 8). In this case the mean pressure values ranged between 894 mbar (day 8) and 622 mbar (day 35).

\subsection{Methane production in the BMP test under P0 and P1 conditions}


In Fig. 2 the cumulative methane production for the CS, the WCG and the DM from experiments P0 and P1 are compared. Under P0 condition, after 35 days of the test the results have shown methane productions of $213 \pm 10,135 \pm 4$ and $31.2 \pm 0.4 \mathrm{~L} \mathrm{CH}_{4} \mathrm{~kg}^{-}$ ${ }^{1}$ substrate for the CS, the WCG and the DM respectively. A lag time in WCG0 can be observed from the shape of the BMP curves in Figure 2 (P0 condition). This lag time is related to the different pressure profile between WCG and the other substrates. Based on the VS added, these methane yields were $259 \pm 12$, $338 \pm 10$ and $262 \pm 3 \mathrm{~L} \mathrm{CH}_{4} \mathrm{~kg}^{-1} \mathrm{VS}$ for the CS, the WCG and the DM respectively. Under P1 conditions the results were $218 \pm 4,124 \pm 4$ and $30.2 \pm 1.8 \mathrm{~L} \mathrm{CH}_{4} \mathrm{~kg}^{-1}$ substrate for the CS, the WCG and the DM respectively.

In the case of the CS and the DM, the statistical analysis showed that there were no significant differences between the methane yields observed in P0 and P1. However, for the WCG the statistical analysis showed no significant differences in the first P1 point (day 4), but as can be observed in Fig. 2 there were significant differences among the rest of the points (days 8, 19 and 35). It was also observed that the differences between P0 and P1 experiments were progressively reduced. At day 8 methane yield in P1 was 25.6\% lower compared to P0; at day 19 the methane yield in P1 was 15.8\% lower whereas at day 35 the methane yield in P1 was only 8.5\% lower compared to P0. It suggests that a longer period of experimentation could have resulted in lower differences between the total methane production under P0 and P1 conditions. At the end of the experiments, the content of the different reactors was analyzed to determine the $\mathrm{pH}$ of the medium and the presence of VFA. The $\mathrm{pH}$ of the reactors were the following: $7.41 \pm 0.01$ for CS0 and $7.37 \pm 0.01$ for CS1; $7.27 \pm 0.02$ for WCG0 and $7.21 \pm 0.01$ for WCG1; $7.33 \pm 0.01$ for DM0 and $7.30 \pm 0.02$ for DM1. The CS and the DM reactors did not show any presence of VFA under any condition at the end of the 
experimentation. In the case of the WCG, no VFA were detected for P0 condition but a mean value of $537 \pm 104 \mathrm{mg} \mathrm{COD}_{\mathrm{VFA}} \mathrm{L}^{-1}$ was detected in the reactors where WCG1 were digested (acetic acid was the predominant VFA (304 $\pm 60 \mathrm{mg} \mathrm{L}^{-1}$ ), followed by propionic acid $\left(78 \pm 17 \mathrm{mg} \mathrm{L}^{-1}\right)$ ). This corroborates the different results observed between experiments WCG0 and WCG1.

\section{Discussion}

To explain the differences between the results observed for the CS and the DM compared to the WCG, a literature review of biogas generation of the substrates employed shows that anaerobic digestion of animal manure has been widely demonstrated and researched (Lisboa and Lansing, 2014). Dairy manure is a relatively easy substrate to digest and the main problem of this substrate is often associated with poor methane yields due to high water content (Mata Alvárez et al., 2014). Labatut et al., (2011) reported an specific methane potential value of $243 \pm 59 \mathrm{~L} \mathrm{CH}_{4} \mathrm{~kg}^{-1}$ VS for dairy manure, which is in accordance with the value obtained in the present work. With regards to CS, according to the Web of Knowledge (October 2015), there are no published research papers dealing with its anaerobic digestion. Thus, there are no references about any possible difficulties in the anaerobic digestion of this waste. There is only a previous work reporting a theoretical methane yield for cocoa shell that was calculated with the Bushwell's formula, resulting in $297 \mathrm{~L} \mathrm{CH}_{4} \mathrm{~kg}^{-1}$ VS (Thomsen et al., 2014). The higher methane yield value compared with that obtained in the present work (259 $\mathrm{L} \mathrm{CH}_{4} \mathrm{~kg}^{-1} \mathrm{VS}$ ) can be due to the fact that theoretical methods correspond to maximum methane potential and often over-estimate the methane yields. As for WCG, there are a few number of articles describing its anaerobic digestion. The majority of them are about co-digestion with other organic wastes. Thus, there is limited 
information available on methane yields of WCG alone. Lane (1983) observed a methane yield for waste coffee grounds of 302-352 $\mathrm{L} \mathrm{CH}_{4} \mathrm{~kg}^{-1} \mathrm{TS}$. The literature has reported inhibition problems in the anaerobic digestion due to its composition. Lane (1983) found a decline in gas production due to some unidentified inhibitory compound in the coffee waste. Li et al. (2015) also reported that WCG contains some compounds having a significant negative effect in the biogas production, founding a significant negative effect on propionic acid degradation. Moreover, the high lipids content in WCG has been suggested as problematic for anaerobic digestion of WCG because of their intermediate products from the hydrolysis, the long chain fatty acids, which have potential toxic effects on the activity of methanogens (Li et al., 2015; Qiao et al., 2013). In the present work, the substrates tested were so diluted with water and inoculum that toxicity associated to inhibitory compounds in WCG does not seem to be the reason for the different results observed in experiments WCG0 and WCG1. In this sense, the only evidence that emerges from this study is the presence of a lag phase in the biomethanization of waste coffee grounds.

A second hypothesis to explain the results obtained is the saturation of $\mathrm{CO}_{2}$ in the reactors medium with higher headspace pressures (P1) which could affect the $\mathrm{pH}$ and alter the microbial activity, thus producing a partial inhibition of the process. However, it is not probable because the amount of alkalinity in the medium provided by the inoculum used in the tests should prevent drops in pH. In the case of WCF, $2.1 \mathrm{~g}$ $\mathrm{CaCO}_{3} \mathrm{~g}^{-1} \mathrm{VS}_{\text {WCG }}$ were available in the medium. According to Field et al. (1988), $1 \mathrm{~g}$ $\mathrm{NaHCO}_{3} \mathrm{~g}^{-1} \mathrm{COD}_{\text {biodegradable }}$ should be added in methanogenic activity tests to avoid drops in $\mathrm{pH}$. Moreover, the $\mathrm{pH}$ measured at the end of the test showed a very small difference between WCG0 and WCG1 mediums: 7.27 and 7.21, respectively.

Higher methane concentration dissolved in the medium due to higher pressures could 
be another reason to explain the differences between WCG0 and WCG1. Nevertheless this effect should also have been experienced in tests with CS and DM, in which the results from experiments P0 and P1 showed no significant differences. Furthermore, the presence of VFA in WCG1 medium (537 mg COD $\mathrm{VFA}^{-1}$ ) indicates that methane saturation in the medium is not the cause of the differences found in the experiments. The conversion of the remaining $\mathrm{COD}_{\mathrm{VFA}}$ in WCG1 reactor to $\mathrm{CH}_{4}$ can be made according to the equation 4:

(4) $V_{C H_{4}}(\mathrm{ml})=0.537 \frac{g C O D_{V F A}}{L} \cdot 0.175 \mathrm{~L}\left(V_{\text {medium }}\right) \cdot 350 \frac{\mathrm{mlCH}}{g C O D}=32.9 \mathrm{ml} \mathrm{CH}_{4}$ The difference in methane production between experiments WCG0 and WCG1 (mean values) can be calculated with equation 5:

$$
\text { (5) } \begin{aligned}
\left(Y_{W C G 0}\right. & \left.\left(135.3 \frac{m L C H_{4}}{g W C G}\right)-Y_{W C G 1}\left(123.8 \frac{m L C H_{4}}{g W C G}\right)\right) \cdot 1.65 g \text { WCG } \\
= & 19.0 \mathrm{ml} \mathrm{CH}_{4}
\end{aligned}
$$

The difference between methane potential from VFA in WCG1 and methane yields obtained in BMP tests WCG0 and WCG1 can be due to the fact that some organic matter had not been yet converted in VFA in WCG1.

\section{Conclusions}

The results obtained suggest that headspace pressure in BMP tests can have an influence on the cumulative methane production depending on the substrate tested, which can lead to underestimate the methane potential of some substrates. The CS and the DM were not affected by the high accumulated headspace pressures experimented in this work. However, the BMP test of the WCG was affected by the high headspace 
pressure. The only evidence that emerges from this study is the presence of a lag phase in the biomethanization of the WCG, but with the analyses performed in the present work it is not possible to determine the reasons for these differences. Thus, additional experiments should be performed to allow a better understanding of the headspace pressure effect in BMP tests.

\section{Acknowledgements}

The authors would like to thank the Spanish Ministry of Science and Innovation and the European FEDER funds for providing financial support through project CTM201128042

\section{References}

Adams, R.C., MacLean, F.S., Dixon, J.K., Bennett, F.M., Martin, G.I., Lough, R.C., 1951. The utilization of organic wastes in N.Z.: second interim report of the interdepartmental committee. New Zealand Engineering, 396-424.

Anderson, G.K., Yang, G., 1992. Determination of bicarbonate and total volatile acid concentration in anaerobic digesters using a simple titration. Water Environ. Res. 64, 53-59.

Angelidaki, I., Alves, M., Bolzonella, D., Borzacconi, L., Campos, J.L., Guwy, A.J., Kalyuzhnyi, S., Jenicek, P., van Lier, J.B., 2009. Defining the biomethane potential (BMP) of solid organic wastes and energy crops: a proposed protocol for batch assays. Water Sci. Technol. 59, 927-934.

APHA, 1998. Standard Methods for the Examination of Water and Wastewater, 20th ed. American Public Health Association, Washington, USA. 
Ballesteros, L.F., Teixeira, J.A., Mussatto, S.I., 2014. Chemical, Functional, and Structural Properties of Spent Coffee Grounds and Coffee Silverskin. Food Bioprocess Technol. 7, 3493-3503.

Chen, Y., Rößler, B., Zielonka, S., Lemmer, A., Wonneberger, A.M., Jungbluth, T., 2014. The pressure effects on two-phase anaerobic digestion. Appl. Energy 116, 409-415.

Concannon, F., Quinn, M., O`Flaherty, S., Colleran, E., 1988. Automated measurements of the specific methanogenic activity of anaerobic digestion biomass. Biochem. Soc. Transact. 17, 425.

Field, J., Sierra, R., Lettinga, G., 1988. [Anaerobic assays]. In: Fdz.-Polanco, F., García, P.A., Hernando, S. (Eds.), [4 $4^{\text {th }}$ Seminar on Anaerobic Wastewater Treatment]. Valladolid, Secretariat Publications. University of Valladolid, Spain, pp. 52-81, Spanish.

Godin, B., Mayer, F., Agneessens, R., Gerin, P., Dardenne, P., Delfosse, P., Delcarte, J., 2015. Biochemical methane potential prediction of plant biomasses: Comparing chemical composition versus near infrared methods and linear versus non-linear models. Bioresour. Technol. 175, 382-390.

ISO 11734, 1995. Water quality - Evaluation of the "Ultimate” Anaerobic Biodegradability of Organic Compounds in Digested Sludge - Method by Measurement of the Biogas Production, ISO Guideline 11734. European Committee for Standardization, Brussels.

Koch, K., Fernández, Y.B., Drewes, J.E., 2015. Influence of headspace flushing on methane production in Biochemical Methane Potential (BMP) tests. Bioresour. Technol. 186, 173-178.

Labatut, R.A., Angenent, L.T., Scott, N.R., 2011. Biochemical methane potential and 
biodegradability of complex organic substrates. Bioresour. Technol. 102, 22552264.

Lane, A.G., 1983. Anaerobic digestion of spent coffee grounds. Biomass 3, 247-268.

Lesteur, M., Bellon-Maurel, V., Gonzalez, C., Latrille, E., Roger, J.M., Junqua, G., Steyer, J.P., 2010. Alternative methods for determining anaerobic biodegradability: A review. Process Biochem. 45, 431-440.

Li, Q., Qiao, W., Wang, X., Takayanagi, K., Shofie, M., Li, Y., 2015. Kinetic characterization of thermophilic and mesophilic anaerobic digestion for coffee grounds and waste activated sludge. Waste Manage. 36, 77-85.

Lindeboom, R.E.F., Fermoso, J., Weijma, J., Zagt, K., van Lier, J.B., 2011.

Autogenerative high pressure digestion: anaerobic digestion and biogas upgrading in a single step reactor system. Water Sci. Technol. 64, 647-653.

Lindeboom, R.E.F., Weijma, J., van Lier, J.B., 2012. High-calorific biogas production by selective $\mathrm{CO}_{2}$ retention at autogenerated biogas pressures up to 20 bar. Environ. Sci. Technol. 46, 1895-1902.

Lisboa, M.S., Lansing, S., 2014. Evaluating the toxicity of food processing wastes as co-digestion substrates with dairy manure. Waste Manage. 34, 1299-1305.

Mata-Alvárez, J., Dosta, J., Romero-Guiza, M.S., Fonoll, X., Peces, M., Astals, S., 2014. A critical review on anaerobic co-digestion achievements between 2010 and 2013. Renew. Sust. Energy Rev. 36, 412-427.

Murovec, B., Kolbl, S., Stres, B., 2015. Methane Yield Database: Online infrastructure and bioresource for methane yield data and related metadata. Bioresour. Technol. 189, 217-223.

Nkemka, V.N., Marchbank, D.H., Hao, X., 2015. Anaerobic digestion of paunch in a CSTR for renewable energy production and nutrient mineralization. Waste 
Manage. 43, 123-129.

Parajuli, P., 2011. Biogas measurement techniques and the associated errors. Master Thesis, University of Jyväskylä, Finland.

Qiao, W., Takayanagi, K., Shofie, M., Niu, Q., Yu, H.Q., Li, Y., 2013. Thermophilic anaerobic digestion of coffee grounds with and without waste activated sludge as co-substrate using a submerged AnMBR: System amendments and membrane performance. Bioresour. Technol. 150, 249-258.

Rozzi, A. and Remigi, E., 2004. Methods of assessing microbial activity and inhibition under anaerobic conditions: a literature review. Rev. Environ. Sci. Biotechnol. 3, 93-115.

Serra J., Benería, M., 1998. Composition of dietary fibre in cocoa husk. Z Lebensm Unters Forsch A. 207, 105-109.

Strömberg, S., Nistor, M., Liu, J., 2014. Towards eliminating systematic errors caused by the experimental conditions in Biochemical Methane Potential (BMP) tests. Waste Manage. 34, 1939-1948.

Thomsen, S.T., Kádár, Z., Schmidt, J.E., 2014. Compositional analysis and projected biofuel potentials from common West African agricultural residues. Biomass Bioenergy 63, 210-217.

VDI 4630, 2006. Fermentation of Organic Materials - Characterisation of the Substrate, Sampling, Collection of Material Data, Fermentation Tests, VDI Guideline 4630. Verein Deutscher Ingenieure, Düsseldorf. 


\section{Figure captions}

Figure 1. Pressure profiles for cocoa shell (CS), waste coffee grounds (WCG) and dairy manure (DM): CS0, WCG0 and DM0 correspond to frequent venting (low headspace overpressure conditions, P0 condition, continuous lines); CS1, WCG1 and DM1 correspond to headspace overpressure within the range $800 \pm 200$ mbar (P1 condition, dotted lines). Curves for P1 conditions are estimated from control reactors. Mean values \pm SD (bars) from triplicate assays.

Figure 2. Biochemical methane potential (BMP) curves for cocoa shell (CS), waste coffee grounds (WCG) and dairy manure (DM): CS0, WCG0 and DM0 correspond to frequent venting (low headspace overpressure conditions, P0 condition, the continuous lines represent the mean values, the dotted lines represent the standard deviation); CS1, WCG1 and DM1 correspond to headspace overpressure within the range $800 \pm 200$ mbar (P1 condition, single points \pm SD bars). Mean values \pm SD from triplicate assays. 
Table 1. Characteristics of cocoa shell, waste coffee grounds, dairy manure and inoculum used in the present study (Mean $\pm \mathrm{SD}, \mathrm{n}=3$ ).

\begin{tabular}{|c|c|c|c|c|}
\hline Parameter & CS & WCG & DM & $\mathbf{I}$ \\
\hline TS (\%) & $89.9 \pm 1.1$ & $40.6 \pm 0.3$ & $13.6 \pm 0.4$ & $2.26 \pm 0.04$ \\
\hline VS (\%) & $82.3 \pm 1.2$ & $40.0 \pm 0.3$ & $11.9 \pm 0.4$ & $1.35 \pm 0.03$ \\
\hline VS/TS & $0.92 \pm 0.01$ & $0.99 \pm 0.01$ & $0.88 \pm 0.01$ & $0.60 \pm 0.01$ \\
\hline TKN (g N kg ${ }^{-1}$ TS) & $25.3 \pm 0.2$ & $23.9 \pm 0.3$ & $23.0 \pm 0.9$ & $44.5 \pm 1.2$ \\
\hline $\mathrm{C} / \mathrm{N}^{*}$ & $20.2 \pm 0.1$ & $22.9 \pm 0.1$ & $21.2 \pm 0.4$ & $7.5 \pm 0.1$ \\
\hline $\mathbf{p H}$ & --- & --- & --- & $7.7 \pm 0.0$ \\
\hline $\mathrm{BA}\left(\mathrm{g} \mathrm{CaCO}_{3} \mathrm{~L}^{-1}\right)$ & --- & --- & --- & $18.9 \pm 0.1$ \\
\hline
\end{tabular}

${ }^{*} \mathrm{C} / \mathrm{N}$ was calculated assuming the carbon content of substrates are $55 \%$ of the VS content (Adams et al., 1951) 
Table 2. Data related to the BMP tests of the studied samples under $\mathrm{P} 0 *$ and $\mathrm{P} 1$ * conditions. Amounts of substrate, water, inoculum and $\mathrm{VS}_{\mathrm{I}} / \mathrm{VS}_{\mathrm{S}}$ ratios. Mean values $\pm \mathrm{SD}$ from triplicate assays.

\begin{tabular}{ccccc}
\hline & Substrate (g) & Inoculum (g) & Water $(\mathbf{g})$ & VS $_{\mathbf{I}} / \mathbf{V S}_{\mathbf{S}}$ \\
\hline CS & $0.66 \pm 0.01$ & $74.34 \pm 0.01$ & $100 \pm 0.01$ & $1.85 \pm 0.03$ \\
WCG & $1.65 \pm 0.02$ & $73.35 \pm 0.02$ & $100 \pm 0.01$ & $1.50 \pm 0.02$ \\
DM & $4.66 \pm 0.11$ & $70.34 \pm 0.11$ & $100 \pm 0.01$ & $1.87 \pm 0.05$ \\
\hline
\end{tabular}

*P0 corresponds to frequent venting (low headspace overpressure conditions); P1 condition corresponds to headspace overpressure within the range $800 \pm 200$ mbar 

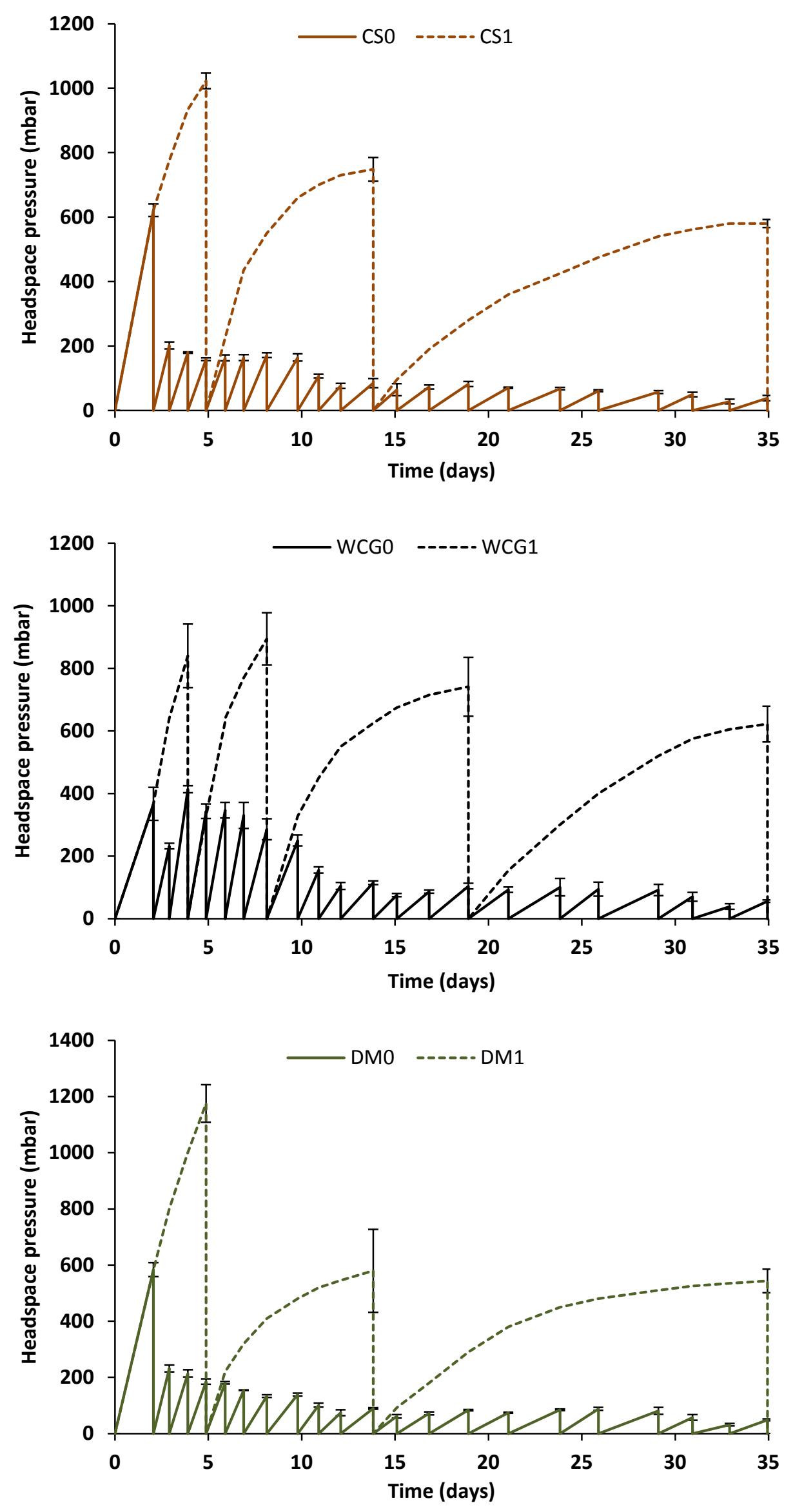

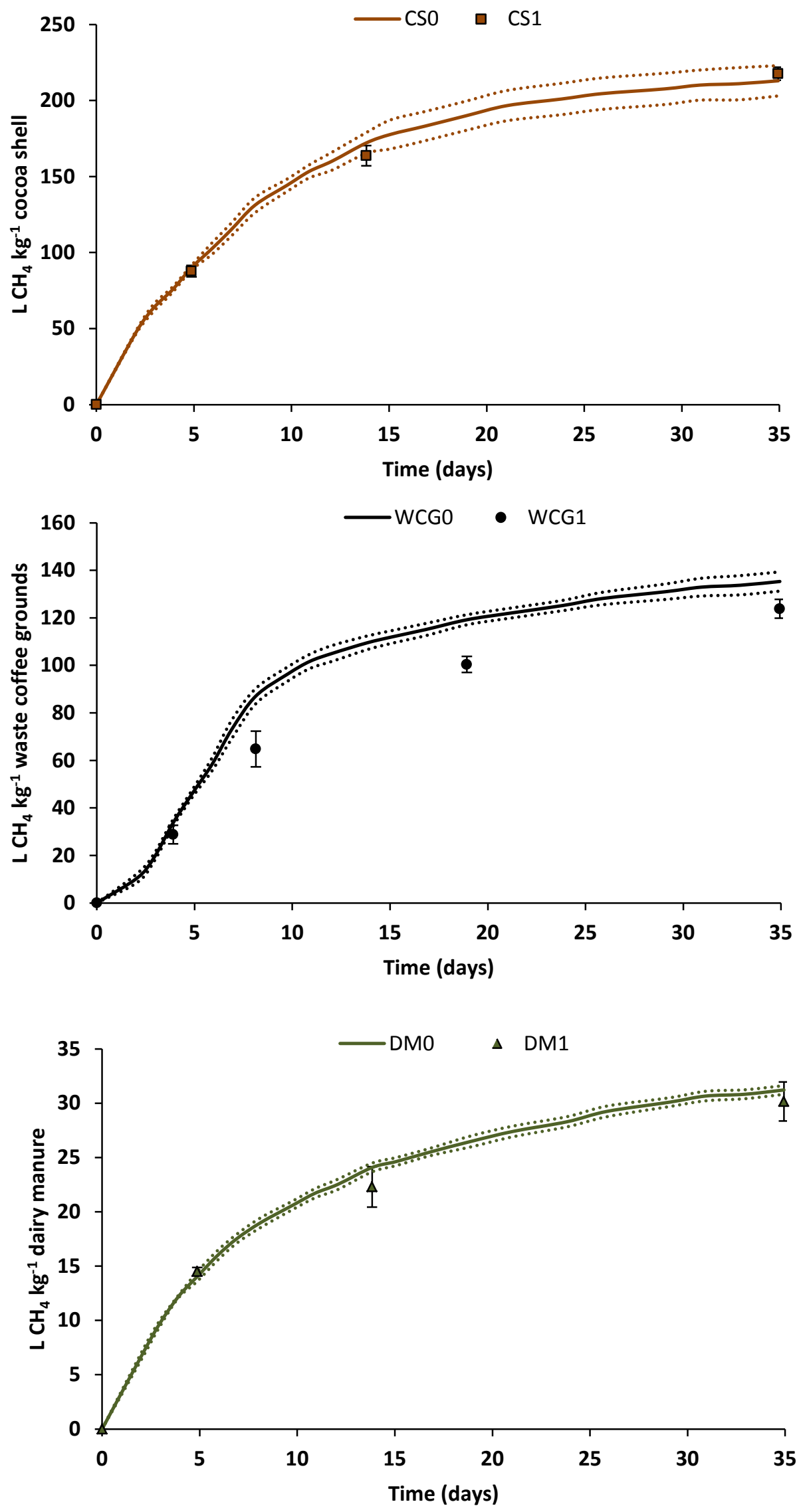